\title{
Genetic evidence for allopatric speciation of the Siberian ibex Capra sibirica in India
}

\author{
Bheem Dutt Joshi ${ }^{1}$, Gul Jabin ${ }^{1,2}$, Amira Sharief ${ }^{1}$, Vineet Kumar ${ }^{1}$, Tanoy Mukherjee ${ }^{1}$, \\ Manish Kumar ${ }^{1}$, Ashutosh Singh ${ }^{1}$, Sujeet Kumar Singh ${ }^{1}$, Kailash Chandra ${ }^{1}$, \\ Lalit Kumar Sharma ${ }^{1}$, Mukesh Thakur ${ }^{1, *}$
}

${ }^{1}$ Zoological Survey of India, New Alipore, Kolkata, 700053 West Bengal, India
${ }^{2}$ Department of Zoology, University of Calcutta, Kolkata, 700019 West Bengal, India

ABSTRACT: Montane systems, formed by a series of climatic oscillations and temporal topographic metamorphoses, have broken up the contiguous distribution of widespread species and accelerated allopatric speciation. We used a partial fragment of the mitochondrial cytochrome $b$ (cytb) gene to address speciation across the entire range of the Siberian ibex Capra sibirica. We demonstrated that the Siberian ibex is a polytypic species, plausibly formed by a combination of at least 2 species and/or 3 to 4 sub-species. Bayesian phylogeny showed that the Indian-Tajikistan (I-T) clade is adequately diverged from the other clades based on the mean intra-specific distance criterion, and warrants recognition as a distinct species. We provide pragmatic evidence for the endorsement of the I-T clade as a distinct species of Siberian ibex and urge prioritization of the conservation of this species at global and regional scales.

KEY WORDS: Siberian ibex $\cdot$ Alpine ibex $\cdot$ Phylogeography $\cdot$ Taxonomic revision $\cdot$ Genetic analysis $\cdot$ Conservation $\cdot$ IUCN Red List

\section{INTRODUCTION}

Climatic oscillations and temporal topographic transformation have been 2 prominent drivers causing vicariance speciation in montane systems (Baker \& Bradley 2006, Drovetski et al. 2013, Yang et al. 2016). Elevated ridges in the montane system often alter habitat and force changes in floral composition, consequently imposing challenges on native species for survival under changing climatic conditions (Manish \& Pandit 2018, Muellner-Riehl 2019). Wild ungulates, which prefer to live in groups with smaller home ranges, have relatively lower ecological resilience, so during historic climatic oscillations and resulting topographic transformation they may plausibly have remained longer in deep clefts in the

\footnotetext{
*Corresponding author: thamukesh@gmail.com
}

mountains, facilitating high intra-specific variation (Lorenzini \& Garofalo 2015, Mukesh et al. 2015, Kumar et al. 2017) and driving allopatric speciation (Outlaw \& Voelker 2008, Pyron \& Burbrink 2010, Xing \& Ree 2017). The central Asian landscape is well-known for its mixed composite of varying habitats, consisting of a chain of low and high elevation mountain ranges that harbor a diverse group of species (Körner 2004, Tamma \& Ramakrishnan 2015). This landscape has been subjected to a series of climatic oscillations and temporal topographic metamorphoses in the past, whereby several species/ subspecies have evolved either through colonization and/or in situ diversification and allopatric speciation (Abramowski et al. 2006, Hörandl \& Emadzade 2012).

(C) The authors 2020. Open Access under Creative Commons by Attribution Licence. Use, distribution and reproduction are unrestricted. Authors and original publication must be credited. 
The distribution of the Siberian ibex Capra sibirica comprises diverse habitats ranging from cold deserts, rocky outcrops, steep terrain, highland flats and mountain ridges to low mountains and foothills (Bhatnagar 1997, Clark et al. 2006, Khan et al. 2016). In Mongolia, its distribution is patchy, and it is mainly found in rugged terrain throughout the western half of the country, as well as in central and south-central Mongolia (Clark et al. 2006). Its distribution further extends towards the Altai, Hangai, Gobi-Altai and Hurkh Mountain Ranges (Schaller et al. 1994, Clark et al. 2006), and it also inhabits the Sayan Mountains near the Russian border, with scattered populations in the small mountains of the Trans-Altai Gobi (Fedosenko \& Blank 2001, Clark et al. 2006, Reading \& Shank 2008, Khan et al. 2016). In Asia, the ibex is found in montane habitats, ranging in elevation from 500-6700 m a.s.l. in, for example, India, Kazakhstan, Kyrgyzstan, Tajikistan, Mongolia, Pakistan, southern Siberia and China (Bhatnagar 1997, Clark et al. 2006, Khan et al. 2016). In India, the Siberian ibex is found mainly in the Trans-Himalayan ranges of Jammu and Kashmir, Union Territory and Himachal Pradesh up to the river Satluj (Fox 1987, Bagchi et al. 2004, Grubb 2005).

Interestingly, it has not yet been established whether the Siberian ibex is a distinct species or a subspecies of C. ibex (Shackleton 1997). However, Wilson \& Reeder (1993) advocated that the Siberian ibex should be considered a distinct species from C. ibex. Further, Pidancier et al. (2006) addressed the evolutionary history of the genus Capra and highlighted speciation and westward migration from the central Asian landscape.

\section{MATERIALS AND METHODS}

\subsection{Sampling and PCR sequencing}

We collected 30 fresh Siberian ibex faecal pellets (9 from Kibber Wildlife Sanctuary, Spiti Valley; 21 from Lahaul Valley) from Himachal Pradesh in northern India (Fig. S1 in the Supplement at www.int-res.com/articles/suppl/n042p001_supp.pdf). Genomic DNA was extracted in a dedicated room using the QIAamp DNA Stool Mini Kit (Qiagen) following the manufacturer's instructions. Polymerase chain reaction (PCR) was used to amplify a partial fragment of the mitochondrial cytochrome $b$ (cytb) gene, using the universal primers developed by Verma \& Singh (2003). The PCR recipe and cycling conditions are detailed in Joshi et al. (2020). The cycle sequencing of PCR products was cleaned up using the Big Dye Terminator kit (Applied Biosystems); purified products were subjected to DNA sequencing on an ABI 3730 genetic analyzer (Applied Biosystems). We retrieved Siberian ibex sequences from GenBank/NCBI (see Table S1 in the Supplement), encompassing the species' entire range in the countries/areas of the Altai Mountains, Kazakhstan, Kyrgyzstan, Russia, Mongolia and the Pamir region of Tajikistan.

\subsection{Data analysis}

The generated raw sequences were proofread with their electropherograms using the software Sequencher v.4.7 (Gene Codes Corporation), and species were validated using the similarity search tool in GenBank (BLAST; https://blast.ncbi.nlm.nih.gov/ Blast.cgi). All sequences were identified as Siberian ibex with 91-99\% identity. Genetic polymorphism, i.e. number of polymorphic sites and haplotypes and sequence divergences, were estimated using the Kimura 2 parameters (K2P) in MEGA v.10 (Kumar et al. 2018). The HKY+G model was found to be most suitable for the nucleotide substitution using the programme Model Generator (Keane et al. 2006). Bayesian inferences were conducted in BEAST v.2.1.3 (Bouckaert et al. 2014). For molecular dating, we used a normal prior with a mean of $2 \%$ per million years (myr), following Johns \& Avise (1998), which is the universal evolutionary rate for the vertebrate $c y t b$ gene. We used a standard deviation equal to $10 \%$ of the mean to account for variation and uncertainty in the rate. Dating analysis was performed for 20 million generations while sampling every $1000^{\text {th }}$ tree, with the first $10 \%$ of trees sampled treated as burn-in; FigTree v.1.3.1 (Rambaut 2009) was used to display and summarize annotated phylogenetic trees yielded by BEAST.

\section{RESULTS AND DISCUSSION}

To unravel the complexity in species recognition of the Siberian ibex, we collected 30 ibex faecal samples from the Lahaul and Spiti District of Himachal Pradesh, India, that yielded 2 haplotypes with an intraspecific sequence divergence (SD) of 0.00-0.004 (Tables S1 \& S2). However, inclusion of published sequences of Siberian ibex from various countries/ areas viz. the Altai Mountains, Kazakhstan, Kyrgyzstan, Russia, Mongolia and the Pamir region of 
Tajikistan showed an intra-specific SD of 0.028-0.118 (Tables S1 \& S3). All Siberian ibex sequences yielded 20 haplotypes, and Bayesian-based phylogeny clustered them into 3 major clades with high posterior probability $(0.9 ;$ Fig. 1$)$ : the I-T clade, representing India and Tajikistan; the KZ clade, representing Kazakhstan; and the AMR clade, representing sequences from the Altai mountains, Mongolia and Russia. Surprisingly, the I-T clade (presently known as the Siberian ibex) was estimated to be more closely related to the the Alpine ibex (divergence during the early Pleistocene epoch, 2.4 myr ago; $95 \%$ CI: $1.4-3.8, \mathrm{SD} 0.041)$ than to the Siberian ibex (divergence during the Miocene-Pliocene boundary, $\sim 6.6$ myr ago; $95 \%$ CI: 4.8-9.4, SD 0.083) (Fig. 1). The I-T clade was found to be adequately diverged from the KZ (SD 0.083) and AMR clades (SD 0.110; Fig. 1) based on the set $10 \times$ threshold of mean intraspecific distance criterion (Kerr et al. 2009, Tobe et al. 2010). The present study indicates that the I-T clade, found in India and Tajikistan, has deeper divergence and is certainly not the same species as the Siberian ibex in the KZ and AMR clades. Interestingly, species divergence between the I-T clade and the Nubian ibex Capra nubiana occurred during the Pliocene epoch ( 3.9 myr ago; CI: 2.4-5.7; SD 0.061). The estimated species divergence time (3-7 myr) reasonably corroborates with other closely related species, e.g. Cervidae (Pitra et al. 2004) and Bovidae (Bibi 2013). Interestingly, the results indicate that diversification events may have occurred during the Pleistocene era, when many areas served as refugia for mammals (Zink et al. 1995, Rodríguez 2004, Byrne et al. 2008, Pavelková Řičánková et al. 2014), as well in the Last Glacial Maximum (Pavelková Řičánková et al. 2015) in central Asia.

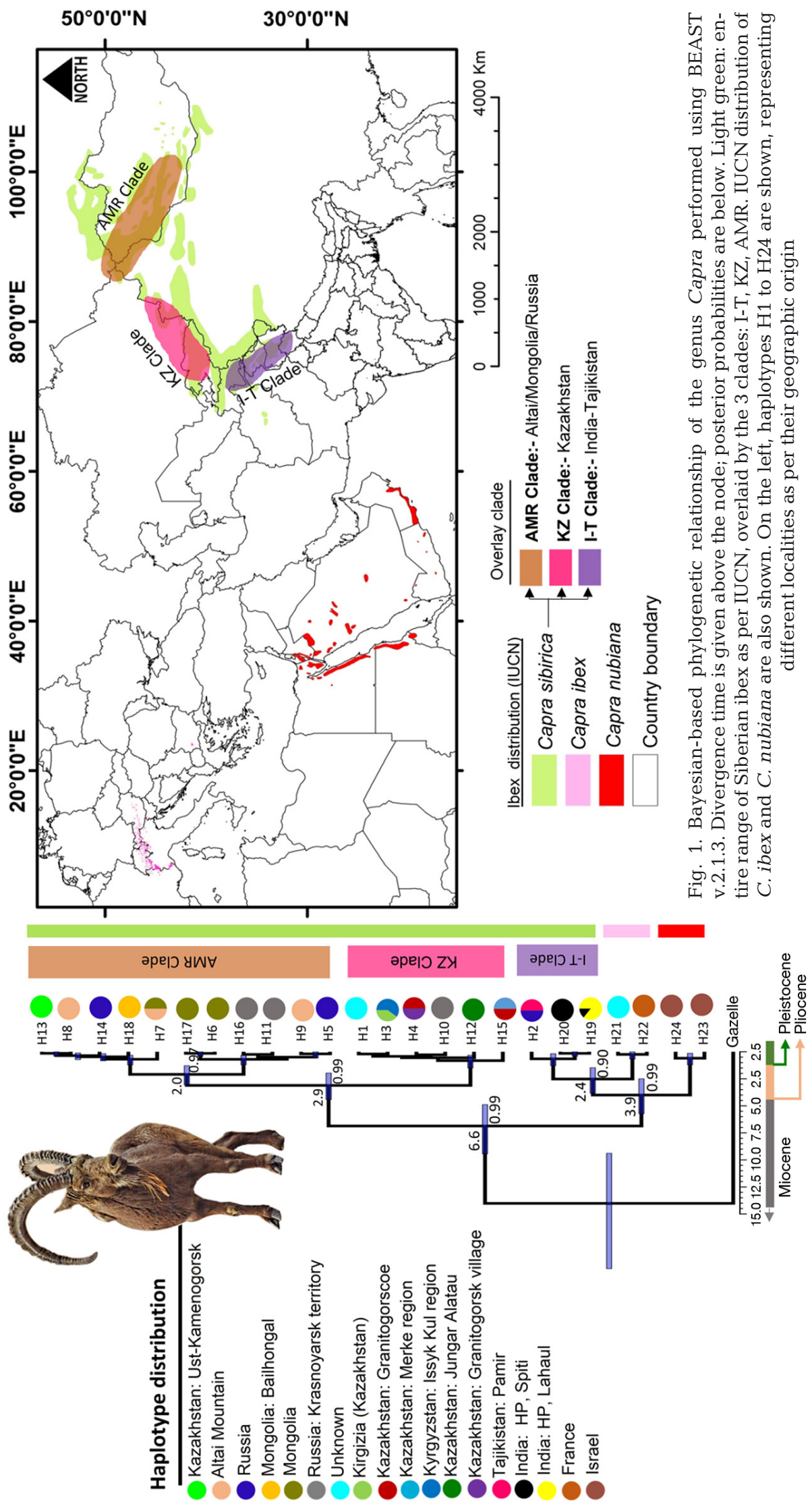


We observed strong phylogeographic structure with respect to the geographical origin of the samples, including different haplotypes in the Lahaul and Spiti Valley from India that support our hypothesis of long isolation histories, possibly due to the influence of climatic-topographic oscillations (Reading \& Shank 2008). Further, the paraphyletic arrangement of clades in the Bayesian phylogeny supports that there are species complexes of Siberian ibex, plausibly comprising at least 2 species (i.e. one being the I-T clade and the other, the KZ/AMR clades), which are then divided into 3 to 4 subspecies (one each of the I-T and KZ clades and 2 of the AMR clade). Evolutionary history suggests that the genus Capra radiated from central Asia (Pilgrim 1947) from 'ibex type' and 'bezoar-type' ancestors, and among these, ibex subsequently bifurcated westward and isolated as 2 separate species i.e. C. ibex and $C$. nubiana (Pidancier et al. 2006). Subsequently, ibex dispersed to India, forming an edge population that was restricted to the Trans-Himalayan ranges of Himachal Pradesh in the western Himalayas.

Our results are based on only a partial fragment of the mitochondrial cytb gene, as this was the only data available for comparison from the entire range of the ibex. However, genes such as cytb and/or cytochrome $c$ oxidase subunit I (COI) have been used in a number of studies, ranging from insects to mammals, for delineating species boundaries (Hebert et al. 2003, Verma \& Singh 2003, Tobe et al. 2010). It is possible that increased sample sizes across the entire ibex distribution and/or using more genes or the whole genome may bring updated insights into the evolutionary history, demography and species diversification of the ibex. However, we believe this would not change the overall species assignment. We seek collaboration to sequence the genomes of ibex from the entire range.

In conclusion, the present study demonstrates that ibex found from India to Tajikistan are adequately diverged from the Siberian ibex found in the Altai Mountains, Russia and Mongolia and show relatively recent divergence from the alpine and Nubian ibex. Further, the Siberian ibex of the Altai Mountains, Russia and Mongolia also significantly diverged from the Kazakhstan population, proving a strong signature of genetic isolation throughout this large landscape. With this study, we advocate that ibex from India to Tajikistan be considered a distinct species, distinct from the Siberian ibex but relatively closer to C. ibex. If the I-T clade is recognized as a distinct species, it will provide the necessary attention to upgrade its conservation status under the IUCN Red
List of Threatened Species and facilitate a call to immediate attention for the conservation and management of the ibex at a global and regional scale.

Author contributions. B.D.J., A.Sh. (A. Sharief), V.K., M.K. and A.Si. (A. Singh) undertook field survey and collected samples. B.D.J., G.J. and S.K.S. participated in data generation, quality check and primary data analysis. T.M. prepared maps and provided all GIS-related support. B.D.J., A.Sh. and G.J. wrote the primary draft of the manuscript. B.D.J. and G.J. raised ideas and conceptualized under the supervision of M.T. and L.K.S. B.D.J., L.K.S. and M.T. finalized the manuscript. L.K.S. and M.T. coordinated the project funded under the National Mission Himalayan Studies (NMHS) of Ministry of Environment, Forest and Climate Change (MoEF\&CC). K.C. supervised the overall activities and provided all the logistic support and administrative approval.

Acknowledgements. We thank the Principal Chief Conservator of Forest (PCCF) and Chief Wildlife Warden (CWLW), Department of Forest, Government of Himachal Pradesh for granting the necessary permission to undertake field surveys. The authors are thankful to Divisional Forest Officers, Lahaul and Spiti Forest Divisions for their consistent support during the field study. We acknowledge the National Mission for Himalayan Studies, Ministry of Environment, Forest and Climate Change (MoEF\&CC) for funding (Grant No. NMHS/2017-18/LG09/02/476).

\section{LITERATURE CITED}

Abramowski U, Bergau A, Seebach D, Zech R and others (2006) Pleistocene glaciations of central Asia: results from ${ }^{10} \mathrm{Be}$ surface exposure ages of erratic boulders from the Pamir (Tajikistan), and the Alay-Turkestan range (Kyrgyzstan). Q Sci Rev 25:1080-1096

*Bagchi S, Mishra C, Bhatnagar YV (2004) Conflicts between traditional pastoralism and conservation of Himalayan ibex (Capra sibirica) in the Trans-Himalayan mountains. Anim Conserv 7:121-128

Baker RJ, Bradley RD (2006) Speciation in mammals and the genetic species concept. J Mammal 87:643-662

Bhatnagar YV (1997) Ranging and habitat utilization by the Himalayan ibex (Capra ibex sibirica) in Pin Valley National Park. PhD dissertation, Saurashtra University, Rajkot

Bibi F (2013) A multi-calibrated mitochondrial phylogeny of extant Bovidae (Artiodactyla, Ruminantia) and the importance of the fossil record to systematics. BMC Evol Biol 13:166

*Bouckaert R, Heled J, Khnert D, Vaughan T and others (2014) BEAST 2: a software platform for Bayesian evolutionary analysis. PLOS Comput Biol 10:e1003537

Byrne M, Yeates DK, Joseph L, Kearney M and others (2008) Birth of a biome: insights into the assembly and maintenance of the Australian arid zone biota. Mol Ecol 17: 4398-4417

Clark EL, Munkhbat J, Dulamtseren S, Baillie JSM and others (2006) Summary conservation action plans for Mongolian mammals. Regional Red List Series, Vol 2. Zoological Society of London, London

Drovetski SV, Semenov G, Drovetskaya SS, Fadeev IV, Red YA, Voelker G (2013) Geographic mode of speciation in a 
mountain specialist avian family endemic to the Palearctic. Ecol Evol 3:1518-1528

Fedosenko AK, Blank DA (2001) Capra sibirica. Mamm Species 675:1-13

Fox JL (1987) Caprini of northwestern India. Caprinae News 2:6-8

Grubb P (2005) Order Artiodactyla. In: Wilson DE, Reeder DM (eds) Mammal species of the world: a taxonomic and geographic reference, $3^{\text {rd }}$ edn. The Johns Hopkins University Press, Baltimore, MD, p 637-722

Hebert PDN, Cywinska A, Ball SL, Jeremy R (2003) Biological identifications through DNA barcodes. Proc R Soc B 270:313-321

*Hörandl E, Emadzade K (2012) Evolutionary classification: a case study on the diverse plant genus Ranunculus L. (Ranunculaceae). Perspect Plant Ecol Evol Syst 14: 310-324

Johns GC, Avise JC (1998) A comparative summary of genetic distances in the vertebrates from the mitochondrial cytochrome $b$ gene. Mol Biol Evol 15:1481-1490

Joshi BD, Sharief A, Kumar V, Kumar M and others (2020) Field testing of different methods for monitoring mammals in Trans-Himalayas: a case study from Lahaul and Spiti. Glob Ecol Conserv 21:e00824

Keane TM, Creevey CJ, Pentony MM, Naughton TJ, McInerney JO (2006) Assessment of methods for amino acid matrix selection and their use on empirical data shows that ad hoc assumptions for choice of matrix are not justified. BMC Evol Biol 6:29

Kerr KCR, Birks SM, Kalyakin MV, Red YA, Koblik EA, Hebert PDN (2009) Filling the gap-COI barcode resolution in eastern Palearctic birds. Front Zool 6:29

Khan G, Khan B, Qamer FM, Abbas S, Khan A, Xi C (2016) Himalayan ibex (Capra ibex sibirica) habitat suitability and range resource dynamics in the central Karakorum National Park, Pakistan. J King Saud Univ Sci 28:245-254

Körner C (2004) Mountain biodiversity, its causes and function. Ambio 13:11-17

Kumar VP, Thakur M, Rajpoot A, Joshi BD and others (2017) Resolving the phylogenetic status and taxonomic relationships of the Hangul (Cervus elaphus hanglu) in the family Cervidae. Mitochondrial DNA A DNA Mapp Seq Anal 28:835-842

Kumar S, Stecher G, Li M, Knyaz C, Tamura K (2018) MEGA $\mathrm{X}$ : molecular evolutionary genetics analysis across computing platforms. Mol Biol Evol 35:1547-1549

Lorenzini R, Garofalo L (2015) Insights into the evolutionary history of Cervus (Cervidae, tribe Cervini) based on Bayesian analysis of mitochondrial marker sequences, with first indications for a new species. J Zool Syst Evol Res 53:340-349

Manish K, Pandit MK (2018) Geophysical upheavals and evolutionary diversification of plant species in the Himalaya. PeerJ 6:e5919

Muellner-Riehl AN (2019) Mountains as evolutionary arenas: patterns, emerging approaches, paradigm shifts, and their implications for plant phylogeographic research in the Tibeto-Himalayan region. Front Plant Sci 10:195

Mukesh, Kumar VP, Sharma LK, Shukla M, Sathyakumar S (2015) Pragmatic perspective on conservation genetics and demographic history of the last surviving population of Kashmir red deer (Cervus elaphus hanglu) in India. PLOS ONE 10:e0117069
Outlaw DC, Voelker G (2008) Pliocene climatic change in insular Southeast Asia as an engine of diversification in Ficedula flycatchers. J Biogeogr 35:739-752

* Pavelková Řičánková V, Robovský J, Riegert J (2014) Ecological structure of recent and last glacial mammalian faunas in northern Eurasia: the case of Altai-Sayan refugium. PLOS ONE 9:e85056

* Pavelková Řičánková V, Robovský J, Riegert J, Zrzavý J (2015) Regional patterns of postglacial changes in the Palearctic mammalian diversity indicate retreat to Siberian steppes rather than extinction. Sci Rep 5:12682

* Pidancier N, Jordan S, Luikart G, Taberlet P (2006) Evolutionary history of the genus Capra (Mammalia, Artiodactyla): discordance between mitochondrial DNA and Y-chromosome phylogenies. Mol Phylogenet Evol 40: 739-749

* Pilgrim GE (1947) The evolution of the buffaloes, oxen, sheep and goats. Zool J Linn Soc 41:272-286

* Pitra C, Fickel J, Meijaard E, Groves PC (2004) Evolution and phylogeny of old world deer. Mol Phylogenet Evol 33:880-895

Pyron RA, Burbrink FT (2010) Hard and soft allopatry: physically and ecologically mediated modes of geographic speciation. J Biogeogr 37:2005-2015

Rambaut A (2009) FigTree, v.1.3.1. http://tree.bio.ed.ac.uk/ software/figtree/

Keading R, Shank C (2008) Capra sibirica. The IUCN Red List of Threatened Species 2008:e.T42398A10695735. https://dx.doi.org/10.2305/IUCN.UK.2008.RLTS.T42398A 10695735.en (accessed 10 Oct 2019)

* Rodríguez J (2004) Stability in Pleistocene Mediterranean mammalian communities. Palaeogeogr Palaeoclimatol Palaeoecol 207:1-22

Schaller GB, Tserendeleg J, Amarsana G (1994) Observations on snow leopards in Mongolia. In: Fox J, Jizeng D (eds) Proc $7^{\text {th }}$ Int Snow Leopard Symp. International Snow Leopard Trust, Xining, p 33-42

Shackleton D (1997) Wild sheep and goats and their relatives: status survey and conservation action plan for Caprinae. IUCN, Gland

*Tamma K, Ramakrishnan U (2015) Higher speciation and lower extinction rates influence mammal diversity gradients in Asia. BMC Evol Biol 15:11

Tobe SS, Kitchener AC, Linacre AMT (2010) Reconstructing mammalian phylogenies: a detailed comparison of the cytochrome $b$ and cytochrome oxidase subunit I mitochondrial genes. PLOS ONE 5:e14156

Verma S, Singh L (2003) Novel universal primers establish identity of an enormous number of animal species for forensic application. Mol Ecol Notes 3:28-31

Wilson DE, Reeder DM (eds) (1993) Mammal species of the world: a taxonomic and geographic reference, $2^{\text {nd }}$ edn. Smithsonian Institution Press, Washington, DC

Xing Y, Ree RH (2017) Uplift-driven diversification in the Hengduan Mountains, a temperate biodiversity hotspot. Proc Natl Acad Sci USA 114:E3444-E3451

Yang A, Dick CW, Yao X, Huang H (2016) Impacts of biogeographic history and marginal population genetics on species range limits: a case study of Liriodendron chinense. Sci Rep 6:25632

Zink RM, Rohwer S, Andreev AV, Dittmann DL (1995) Trans-Beringia comparisons of mitochondrial DNA differentiation in birds. Condor 97:639-649 